\title{
SYNTHESIS, CHARACTERIZATION, AND IN VIVO IMMUNOMODULATION OF CCR2 AND VASCULAR ENDOTHELIAL GROWTH FACTOR ANTAGONISTS-LOADED PEGYLATED NANOPARTICLES
}

\author{
AHMED A ABD-RABOU*, HANAA H AHMED, MOHAMED S KISHTA \\ Department of Hormones, Medical Research Division, National Research Centre, Dokki, Giza, Egypt and Stem Cell Lab., Centre of \\ Excellence for Advanced Sciences, National Research Centre, Dokki, Giza, Egypt. *Email: ahmedchemia87@yahoo.com
}

Received: 27 August 2018, Revised and Accepted: 25 October 2018

\begin{abstract}
Objective: Chemokine (C-C motif) ligand 2 (CCL2), a candidate of cytokines, orchestrates immune cell recruitment to inflamed organs. CCL2 has been shown to have direct angiogenic effects, so providing an anti-angiogenic agent, Avastin (AV), to be combined with the CCR2 antagonist (concentration ratio [CR]) plays an essential role in the hemostatic strategy for immunomodulation. Lack of targetability and the adverse effects of chemical treatments are the main obstacles led scientists to develop novel strategies using nano-delivery approaches such as pegylated nanoparticles (NPs) which exhibits reduced drug clearance rates. The rationale of the current study is to test the in vivo immunomodulatory effects of AV and/or CR in their NPs or free counterparts.

Methods: These NPs were synthesized and characterized using different physicochemical techniques. Males Wistar rats (n=114) were used and divided into 7 groups treated with vehicle, AV, AVNP, CCR2 antagonist (CR), CCR2 antagonist NPs (CRNP), AV-CCR2 antagonist (AVCR), and AV-CCR2 antagonist NPs (AVCRNP). Groups were subdivided into three subgroups according to the administrated dose. Blood was taken from rats for differential leukocyte and platelet profile measurements. Sera were collected to test vascular endothelial growth factor (VEGF) levels. Autopsy samples from liver were taken for histopathological investigation.
\end{abstract}

Results: The morphology of the NPs was spherical and had sizes ranging from $89.89 \mathrm{~nm}$ to $146 \mathrm{~nm}$. Monocytes and lymphocytes accumulated in the blood circulation and VEGF levels were inhibited after AV and CR administrations. In addition, large platelets concentration ratio was elevated in the blood circulation.

Conclusion: We concluded that AV ad CR therapeutic regimens have an immunomodulatory role through induction of monocyte-platelet aggregation and inhibition of VEGF.

Keywords: Immunomodulation, Avastin, CCR2 antagonist, Monocyte-platelet connection, Vascular endothelial growth factor.

(c) 2019 The Authors. Published by Innovare Academic Sciences Pvt Ltd. This is an open access article under the CC BY license (http://creativecommons. org/licenses/by/4. 0/) DOI: http://dx.doi.org/10.22159/ajpcr.2019.v12i1.29337

\section{INTRODUCTION}

Chemokine (C-C motif) ligand 2 (CCL2) is a candidate of a cytokines group called "chemokines." CCL2 has a chemoattractant potential and arranges immune cell staffing to precise organs. Its expression is mandatory for homeostatic purposes such as adapting immune cell transferring from blood circulation to an inflamed organ [1]. The expression of CCL2 is found in an extensive range of cells including myeloid, fibroblasts, etc. Importantly, CCL2 binds its receptor CCR2 and acts as a potent chemoattractant for monocytes, lymphocytes, and basophils infiltration from blood to an organ [2].

CCL2 was primarily branded as a monocyte chemotactic protein 1 (MCP-1), and it was considered as one of MCPs family. This family is essential to prompt signal transduction pathways and exerts biological functions such as chemotaxis [3].

CCL2 differently binds its receptor (CCR2), which is expressed in several areas such as blood, kidney, and liver. There are two isoforms of the expressed CCR2 due to splicing process of CCR2A and CCR2B [4].

Apart from CCR2, the ligand (CCL2) may bind other MCP receptors as well. CCL2 was found to bind other receptors such as CCR4 on lymphocytes, resulting in their staffing to melanoma cells, thereafter involving an immune-relevant protective effect against tumor [5]. This recruitment flexibility leads to different biological consequences, depending on the connection between chemokine and its receptor [6]. For instance, binding of CCL7/2 with CCR2 may inspire monocyte expatriation from the bone marrow to the site of interest [7]. Similarly, binding CCL8/2 with CCR2 on colorectal cancerous cells may incite a comparable induction in angiogenesis and metastasis [8]. Considering the explicit immunomodulatory effects of CCL2-CCR2 signaling is an inspiring aspect. However, the link between CCL2 and CCR2 appears to be a ubiquitous connection with silenced CCL2, resulting in similar phenotypes of those deficient in CCR2 $[9,10]$.

Monocytes, a group of leukocytes that articulates chemokine-related receptors, are originally produced in the bone marrow and are unconstrained into the blood circulation [11]. The CCL2 receptor (CCR2) is found on monocytes that are related with immune protection against inflammation [12].

CCL2-CCR2 signal defends prostate cancer cells through induction of programmed death by PI3K/Akt/survivin path [13]. In addition to effects on tumor cells, CCL2 also intervenes stromal cell replies in the prostate cancer environment. CCL2 blockade using a specific antibody in in vivo model suppressed tumor development, reduced macrophage permeation, and led to compact tumor-related vasculature [14]. Although CCL2 was exposed to have angiogenic effects in many reports, another story proved that it stimulated cancer cells to upregulate the vascular endothelial growth factor (VEGF) expression as an angiogenic factor [15]. Thus, providing an anti-VEGF agent, like Avastin (AV), to be combined with the CCR2 antagonist in the current study gaining a hemostatic strategy for an in vivo immunomodulation. Anti-VEGF therapy reduced vessel size and tortuosity with more pericyte coverage of the remaining normalized vessels [16]. 
Lack of targetability and instability in addition to adverse effects of chemical-based treatments are the main obstacles led scientists to develop novel strategies to tackle diseases using nano-delivery approaches [17-21]. Recently, several delivery systems were developed by utilizing pegylated products [22]. These procedures augmented the half-life and bustle of drugs, and diminished liver toxicity [23].

Overall, the rationale of the current study is to test the immunom odulatory effects of the anti-VEGF AV and/or CCR2 antagonist (CR) in their pegylated nanoformulation or free counterparts, understanding the mechanisms modulating immunity in rats to get closer to suggest some further recommendations regarding angiogenesis-mediated immunomodulation through targeting liver microenvironment which may gain great success in cancer eradication in near future.

\section{MATERIALS AND METHODS}

Materials

Methoxypolyethyleneglycolamine(mPEG-NH $\left.\mathrm{N}_{2}, \mathrm{MW} 5000 \mathrm{Da}\right), 1$-ethyl-3-(3dimethylaminopropyl)-carbodiimide(EDC), N-hydroxysuccinimide(NHS), heparin (HP), PEG (MW 5000 Da), 2-(N morpholine) ethanesulfonic acid (MES), dimethyl sulfoxide, Tween 80, and poly L-lysine (PLL), and CCR2 antagonist RS 504393 (CR) were purchased from Sigma-Aldrich, USA. Bevacizumab AV was purchased from Genentech Inc., USA. Ultrapure water (Millipore, Bedford, MA, USA) was used.

\section{Preparation of $A V$ and $C R$ nanoparticles (NPs) \\ Nano-void (NV) synthesis}

According to a previous method mentioned in Lim et al. [24], we used it with some modifications to prepare PEG-exposed NPs (NV). To prepare NV, we first prepared the mixture of EDC and NHS. Briefly, HP (HP: $0.1 \mathrm{mMol}$ ) was coupled with $0.1 \mathrm{mM}$ of mPEG-NH2 (MW $5000 \mathrm{Da}$ ) using EDC (1.5 mMol) and NHS (1.6 mMol) in MES buffer (0.1 M, pH 5.5) at room temperature for $24 \mathrm{~h}$ stirring. Then, $\mathrm{NV}$ was prepared simply by mixing the polymer (PEG-HP) with PPL buffer (6:1 v/v ratio) overnight at $4^{\circ} \mathrm{C}$.

\section{AVNPs synthesis}

To prepare the PEG-NPs of bevacizumab AV monoclonal antibody (AV NPs); first, the PEG-HP polymer was synthesized as above and the core NPs were prepared by mixing the polymer with PLL buffer overnight at $4^{\circ} \mathrm{C}$ using this ratio (1:6 v/v, PLL: PEG-HP). Then, AV NPs were synthesized by activating the amine groups in the formed NPs mixture using EDC and NHS to bind with the carboxylic groups in $25 \mathrm{mg} / \mathrm{mL}$ monoclonal antibody (AV) by stirring overnight at $4^{\circ} \mathrm{C}$, after that amide bonds were formed and the AVNPs were functionalized.

\section{CCR2 antagonist NPs synthesis}

To prepare the PEG-NPs of CCR2 antagonist RS 504393 (CRNPs), simply the PEG-HP polymer was synthesized as above, and the CRNPs were prepared by mixing the polymer with PLL buffer overnight at $4^{\circ} \mathrm{C}$ using this ratio (1: $6 \mathrm{v} / \mathrm{v}$, PLL: PEG-HP). Before adding PLL to form the CR NPs, $2 \mathrm{mg} / \mathrm{mL}$ CCR2 antagonist RS 504393 of CR was titrated to the PEG/HP polymer. This mixture was vortexed for $5 \mathrm{~min}$ and subsequently sonicated for $5 \mathrm{~min}$ using a Sonics Vibra-cell sonifier VC750 equipped with a micro-tip (Newtown, CT) at amplitude $=35 \%$, pulse-on $=5.0 \mathrm{~s}$, and pulse-off $=3.0 \mathrm{~s}$. The suspension was transferred to a round-bottom tube in a water bath with magnetic stirring overnight at room temperature.

\section{AV-CR NPs synthesis}

To prepare AV-CRNPs, first, the CRNPs were synthesized as a core vehicle (as mentioned above) then the amine groups were activated using EDC and NHS to bind the carboxylic groups in $25 \mathrm{mg} / \mathrm{mL}$ monoclonal antibody (AV) by stirring overnight at $4^{\circ} \mathrm{C}$, after that amide bonds were formed, and the AV-CRNPs were functionalized.

\section{NPs characterization}

Dialysis technique and measurement of the encapsulation efficiency

All nano-samples were divided into two portions; (1) one for measuring the total concentrations of the free plus nano-conjugated AV and CR and (2) the second part for measuring the concentrations of the nano-conjugated $\mathrm{AV}$ and $\mathrm{CR}$ after performing dialysis tubing technique for eliminating the impurities and the free drug using a membrane bag (Spectra/Por Membrane, Spectrum Laboratories, USA; molecular weight cut-off, MWCO: 25,000 Da).

The free and conjugated forms of $A V$ and CCR2 antagonist were detected with a variable wavelength detector using a UV-based ELISA system. The calibration curves for quantification of these compounds were linear over the range of standard concentrations. Finally, encapsulating (entrapment) efficiency (EE) was calculated after dialysis technology.

\section{Transmission electron microscopic (TEM)}

Particle morphology of all NPs was examined by TEM (TEM, Philips CM-10, FEI Inc., Hillsboro, OR, USA). $100 \mu \mathrm{g} / \mathrm{ml}$ of the nano-suspensions were dropped into formvar-coated copper grids, and after complete drying, the samples were stained using 2\% w/v Uranyl Acetate (Electron Microscopy Services, Ft. Washington, PA). Image capture and analysis were done using Digital Micrograph and Soft Imaging Viewer Software.

\section{Particle size distribution and zeta potential}

The particle size and zeta potential analyses of all NPs were performed by photon correlation spectroscopy (PCS) and laser diffractometry (LD). For PCS measurements, $1 \mathrm{~mL}$ of the NPs solution was filled in the disposable transparent sizing clear cuvette, and the size of the sample was analyzed at $25^{\circ} \mathrm{C}$ with a Malvern Zetasizer (Malvern Instruments, Westborough, Massachusetts). All measurements were performed in triplicate.

\section{Fourier transform infrared spectroscopy (FTIR)}

FTIR spectra of PEG-amine, HP, PLL, MES, NVNPs, AVNPs, CRNPs, and AV-CRNPs were determined using Bruker Vector 22 FTIR. The spectra were obtained in the range of $500-4000 \mathrm{~cm}^{-1}$.

\section{In vivo application}

Animals

A total of $114 \quad(n=114)$ male Albino rats of Wistar strain (body weight 100-120 g) were used in this study. Animals will be obtained from the Animal House Colony at National Research Centre, Giza, Egypt. The animals were housed in a specific pathogen-free barrier area in a room with controlled temperature $\left(22 \pm 1^{\circ} \mathrm{C}\right)$ and humidity $(50 \pm 10 \%)$ and a $12 \mathrm{~h} \mathrm{light/dark}$ cycle. The rats were allowed ad libitum access to water and standard laboratory diet consisting of casein $10 \%$, salts mixture $4 \%$, vitamins mixture $1 \%$, corn oil $10 \%$, and cellulose $5 \%$ completed to $100 \mathrm{~g}$ with cornstarch [25]. The study protocol followed the guidelines approved by the Ethical Committee of the Medical Research of the National Research Centre (Approval No. 16/281).

\section{Experimental design}

A total of 114 males $(n=114)$ of Wistar rats were used in the current study and divided into 7 groups. All groups were treated daily for 30 days with vehicle (Group 1, control, $\mathrm{n}=6$ ), AV (Group 2, $\mathrm{n}=18$ ), AVNP (Group 3, n=18), CR (Group 4, n=18), CRNP (Group 5, n=18), AVCR (Group 6, n=18), and AVCRNP (Group 7, n=18). Groups (2-7) were subdivided into three subgroups ( $\mathrm{n}=6$ in each subgroup) according to the administrated dose (high safe dose, D1; half safe dose, D2; and quarter safe dose, D3). These doses (showed in Table 1) were administrated orally and determined according to a preliminary study that was performed about acute and chronic toxicity of these nano-formulations in vivo.

\section{Blood sampling and biochemical investigations}

At the end of the experimental period, rats were fasted overnight and subjected to diethyl ether anesthesia. Blood samples were 
immediately collected from the retro-orbital venous plexus and divided into two portions, the first portion was collected using vacutainer tubes containing ethylenediaminetetraacetic acid (EDTA) (BD Company, Canada) for differential leukocytes and platelets, while the second portion was be left to clot in clean, dry test tubes, and then centrifuged at $\times 1800 \mathrm{~g}$ for $10 \mathrm{~min}$ to obtain sera. The clear supernatant sera were used for VEGF concentration measurements.

From sampling to differential leukocytes and platelets measurement Medonic M32 analyzer included MPA micro-pipette adapter for sampling (Boule Diagnostics AB Company, Sweden) was used for complete blood count (CBC) of rat blood samples which collected using vacutainer tubes containing EDTA (BD Company, Canada). $20 \mu \mathrm{L}$ of blood samples were collected from the vacutainer tubes and simply drawn into the micro-capillary tube connected with the MPA micro-pipette adapter for CBC analysis. Medonic M32 analyzer comes equipped with a high-precision shear-valve for getting accurate results of hematology analysis. Hematological analysis is concerned with the analysis of the cellular component of blood including tests that used for evaluation of erythrocyte, leukocyte, and platelet pictures. Different parameters were analyzed as follow: Total white blood cells (WBC), differential leukocyte count (lymphocytes percentage, monocytes percentage, and granulocytes percentage), platelet count (PLT), the amount of blood occupied by platelets (platelet crit; PCT), the average volume of platelet (mean platelet volume [MPV]), the variation in size of platelets in the blood circulation (platelets distribution width [PDW]), and the concentration of the LP in the blood circulation (LP concentration ratio [LPCR]).

\section{VEGF level measurement using ELISA}

Rat VEGF ELISA Kit (Cat. No. E-EL-R0020, Elabscience Biotechnology Co., USA) was used for quantitative determination of rat VEGF concentrations in rat sera after the different treatments compared to control. The principle of this kit is based on the sandwich-ELISA method. Briefly, we have drawn a standard curve using the provided VEGF standard. The standard working solution was prepared by centrifuging the standard at $\times 10,000 \mathrm{~g}$ for $1 \mathrm{~min}$. Then, $1 \mathrm{~mL}$ of the provided reference standard and sample diluent was added and left for 10 min by mixing gently. The reconstitution produced a working solution of $2000 \mathrm{pg} / \mathrm{mL}$, then we made serial dilutions as follows: 2000 , $1000,500,250,125,62.5,31.25$, and $0 \mathrm{pg} / \mathrm{mL}$. We started the procedure with adding $100 \mu \mathrm{L}$ of the prepared standard or sample to each well, then they were incubated for $90 \mathrm{~min}$ at $37^{\circ} \mathrm{C}$, thereafter the liquid was removed. We diluted the biotinylated detection $\mathrm{Ab}(1: 100)$ and left it for 15 min earlier before adding $100 \mu \mathrm{L}$ of it to each well; then the plate was incubated for $1 \mathrm{~h}$ at $37^{\circ} \mathrm{C}$. The plate was aspirated and washed for 3 times. We diluted the concentrated horseradish peroxidase (HRP) conjugate (1: 100) and left it for 15 min earlier before adding $100 \mu \mathrm{L}$ of HRP conjugate to each well; then the plate was incubated for $30 \mathrm{~min}$ at $37^{\circ} \mathrm{C}$. The plate was aspirated and washed for 3 times. $50 \mu \mathrm{L}$ of the provided substrate reagent was added and incubated for $15 \mathrm{~min}$ at $37^{\circ} \mathrm{C}$. The reaction in each well was stopped before reading by $50 \mu \mathrm{L}$ of stop solution, then the OD value at $450 \mathrm{~nm}$ was determined immediately. The OD is proportional to the concentration of rat VEGF. The concentration of rat VEGF was calculated in the samples by comparing the OD of the samples to the diagrammed standard curve.

Table 1: The doses of the administrated therapeutic regimens

\begin{tabular}{llll}
\hline Groups & $\mathbf{M g} / \mathbf{k g}$ & & \\
\cline { 2 - 4 } & High safe dose, & $\begin{array}{l}\text { Half safe dose, } \\
\text { D2 }\end{array}$ & $\begin{array}{l}\text { Quarter safe dose, } \\
\text { D3 }\end{array}$ \\
\hline AV & 5 & 2.5 & 1.25 \\
AVNP & 5 & 2.5 & 1.25 \\
CR & 0.001 & 0.0005 & 0.00025 \\
CRNP & 0.001 & 0.0005 & 0.00025 \\
AVCR & $5+0.001$ & $2.5+0.0005$ & $1.25+0.00025$ \\
AVCRNP & $5+0.001$ & $2.5+0.0005$ & $1.25+0.00025$ \\
\hline
\end{tabular}

From tissue sampling to histopathological investigation

Autopsy samples were taken from the liver of rats in the different groups and fixed in $10 \%$ formol saline for $24 \mathrm{~h}$. Washing of samples was done in tap water then serial dilutions of alcohol (methyl, ethyl, and absolute ethyl) were used for dehydration. Specimens were cleared in xylene and embedded in paraffin at $56^{\circ} \mathrm{C}$ in hot air oven for $24 \mathrm{~h}$. Paraffin bees wax tissue blocks were prepared for sectioning at 4 microns thickness by sledge microtome. The obtained tissue sections were collected on glass slides, deparaffinized, and stained by hematoxylin and eosin stains for examination through the light electric microscope [26].

\section{RESULTS AND DISCUSSION}

\section{Characterization of NPs}

EE

For measuring the EE of AV in the nano-capsules (AVNPs and AV-CRNPs), calibration curve of AV after dialysis tubing was performed. The serial dilutions used for drawing the calibration curve are $0.39,0.78,1.56$, and $3.12 \mathrm{mg} / \mathrm{mL}$ as shown in Fig. 1. The EE of AV in AV NPs was $86 \pm 5.5$ and in $\mathrm{AV}$-CRNPs was $82 \pm 7.0$.

For measuring the EE of CCR2 antagonist (CR) in the nano-capsules (CRNPs and AV-CRNPs), calibration curve after dialysis tubing was performed. The serial dilutions used for drawing the calibration curve are $0.0078,0.0156,0.0312,0.0625$, and $0.125 \mathrm{mg} / \mathrm{mL}$ as shown in Fig. 1. The EE of CR in CR NPs was $74 \pm 2.8$ and in AV-CR NPs was $75 \pm 6.4$.

\section{TEM}

TEM was used for imaging of PEG-based NPs as illustrated in Fig. 2. The morphology of the NV is spherical in shape as illustrated in Fig. 2a. In addition, these spherical NVNPs have sizes ranging from $89.89 \mathrm{~nm}$ to $99.06 \mathrm{~nm}$ as illustrated in Fig. 2b. In Fig. 2c, high scale field $(1 \mu \mathrm{m})$ of AV NPs morphology shows spherical core particles surrounded by monoclonal AV antibody. Sizes of AV NPs were in the range of 145-146 nm. In Fig. 2d, high scale field ( $500 \mathrm{~nm}$ ) of CRNPs morphology shows that spherical particles were illustrated. Sizes of CRNPs were in the range of $57.7-73.36 \mathrm{~nm}$.

Fig. 2e shows TEM images of AVCR NPs. It illustrates high scale field $(500 \mathrm{~nm})$ of AV-CRNPs morphology shows spherical core particles surrounded by monoclonal AV antibody. Sizes of AVNPs were in the range of $139-155.65 \mathrm{~nm}$.

\section{Size and zeta potential stability of NPs}

As shown in Fig. 3, size distribution and apparent zeta potential of the NPs were characterized. Representative size distribution $(108.9 \mathrm{~nm})$ of NV was drawn using Malvern ZetaSizer system based on PCS and LD as illustrated in Fig. 3a. In addition, representative zeta potential ( $4.99 \mathrm{mV}$ ) of NV was distributed using Malvern Zetasizer system based on PCS and LD as illustrated in Fig. 3b. Representative size distribution (147.8 nm) of AVNPs was drawn in Fig. 3c. Representative zeta potential ( $-9.05 \mathrm{mV})$ of AVNPs was drawn in Fig. 3d. Representative size distribution $(76.26 \mathrm{~nm})$ of CR NPs was drawn in Fig. 3e. Representative zeta potential $(-2.81 \mathrm{mV})$ of AVNPs was drawn in Fig. 3f. Representative size distribution (293.4 nm) of AV-CRNPs was drawn in Fig. 3g. Representative zeta potential ( $4.71 \mathrm{mV}$ ) of AV-CRNPs was drawn in Fig. 3h.

\section{FTIR spectroscopy}

Schematic diagram (Fig. 4) of NPs was illustrated to figure the vehicle components that incorporated in the nano-encapsulation of all particles. To prepare PEG NPs, we first prepared the mixture of EDC and NHS. Then, NPs were produced simply by mixing the polymer with PLL buffer overnight at $4^{\circ} \mathrm{C}$ with the mix ratio (1:6 v/v, PLL: PEG-HP). NV, AV NPs, CR NPs, and AV-CR NPs encapsulation is accompanied with peptide bond " $\mathrm{O}=\mathrm{C}-\mathrm{NH}$ " formation.

Fig. 5a shows the Fourier Transform infrared spectroscopy (FTIR) of PEG-amine, heparin (HP), poly L-lysine (PLL), MES, and NV NPs 


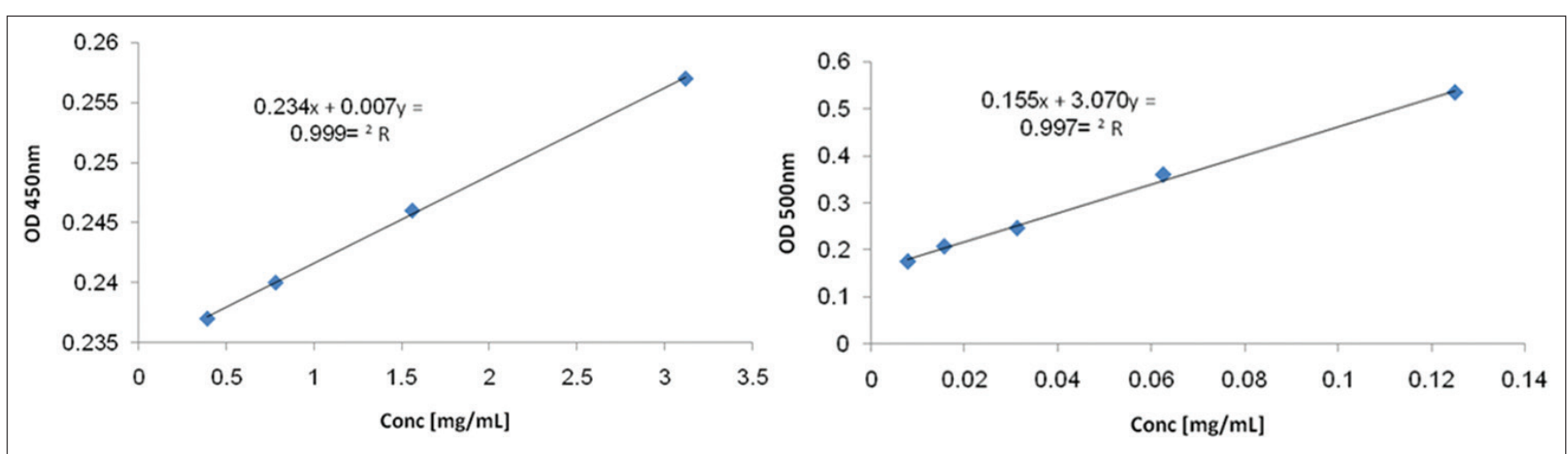

Fig. 1: Calibration curves of Avastin (AV) and CCR2 antagonist (CR) used for measuring entrapment efficiency of AV nanoparticles (NPs), CRNPs, and AV-CRNPs

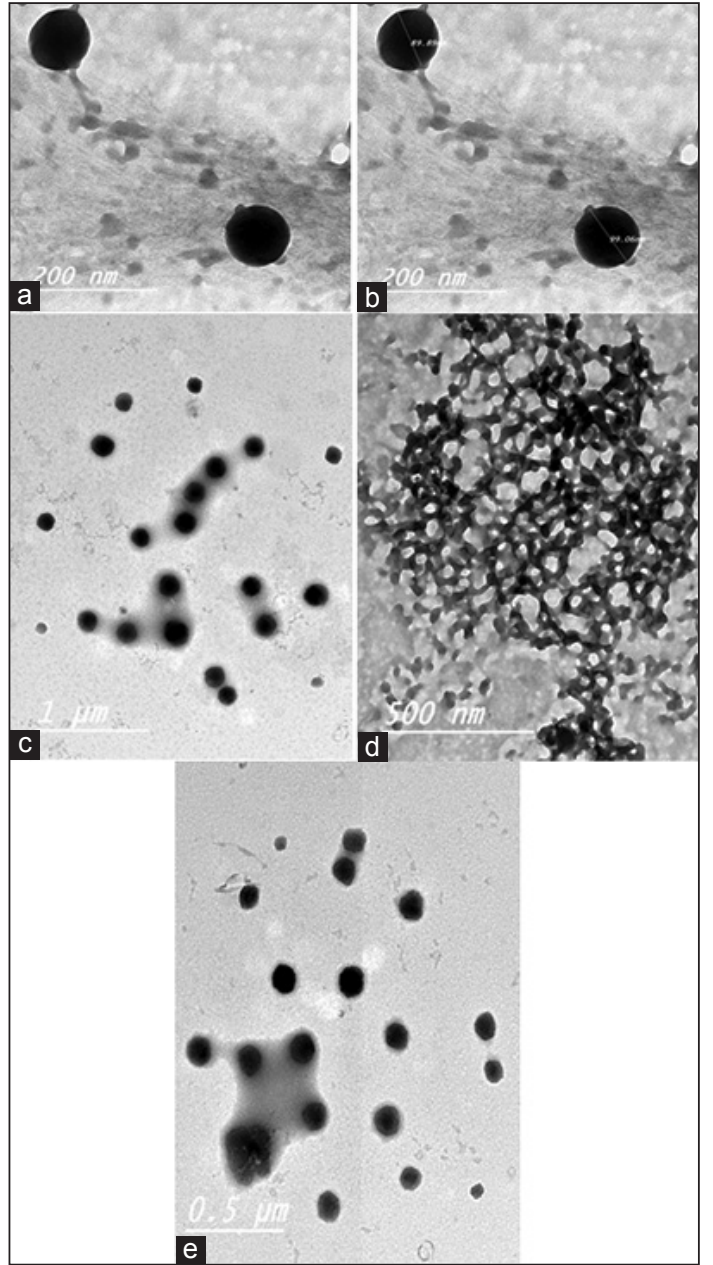

Fig. 2: Transmission electron microscopic analyses. (a) NV morphology was spherical in shape. (b) Sizes of spherical NV nanoparticles (NPs) were $89.89 \mathrm{~nm}$ and $99.06 \mathrm{~nm}$. (c) AVNPs morphology shows spherical core particles surrounded by monoclonal AV antibody. Sizes of AVNPs were in the range of 145-146 nm. (d) CRNPs morphology shows spherical particles. Sizes of CRNPs were in the range of $57.7-73.36 \mathrm{~nm}$. (e) AV-CRNPs morphology shows spherical core particles surrounded by monoclonal AV antibody. Sizes of AVNPs were in the range of $139-155.65 \mathrm{~nm}$

which were determined using Bruker Vector 22 FTIR. The spectra were obtained in the range of $500-4000 \mathrm{~cm}^{-1}$. NV encapsulation is accompanied with amide bond " $\mathrm{O}=\mathrm{C}-\mathrm{NH}$ " formation. On the other hand,
Fig. 5b shows the FTIR of HP and PLL which were magnified to increase clarity. Moreover, FTIR of NV NPs, AV, and AV NPs were determined using Bruker Vector 22 FTIR Fig. 6a. The spectra were obtained in the range of $500-4000 \mathrm{~cm}^{-1}$. NV encapsulation is accompanied with peptide

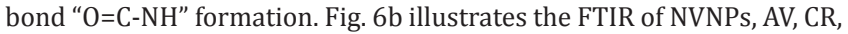
CRNPs, and AV-CRNPs which were determined. Fig. 6c illustrates the FTIR of AV and CR which were magnified to increase clarity

Immunomodulation: Immune cells, platelets, and VEGF network $\mathrm{AV}, \mathrm{AVNP}, \mathrm{CR}, \mathrm{CRNP}, \mathrm{AVCR}$, and AVCRNP played a crucial role in immunomodulation after their administration in vivo rats. In Fig. 7a, monocytes were high significantly $(\mathrm{p}<0.01)$ elevated in blood after treatments with AV, AVNP, CR, CRNP, AVCR, and AVCRNP. This elevation of monocytes led to an accumulation of these immune cells in the circulatory system. This elevation of monocytes led to an accumulation of these immune cells in the circulatory system. We noticed that there was a significant dose-dependent increase $(\mathrm{p}<0.05)$ only in the nanoformulated regimens of $\mathrm{AV}, \mathrm{CR}$, and $\mathrm{AVCR}$, while there was no stable pattern in the case of the free regimens of $A V, C R$, and AVCR. In addition, lymphocytes were significantly $(p<0.05)$ elevated in blood after treatments with AV, AVNP, CR, CRNP, AVCR, and AVCRNP as shown in Fig. 7b. This elevation of lymphocytes led to an accumulation of these immune cells in the circulatory system. We noticed that there was a significant dose-dependent increase $(\mathrm{p}<0.05)$ of lymphocytes only in the individual regimens including $\mathrm{AV}, \mathrm{AVNP}, \mathrm{CR}$, and CRNP, while there was a significant dose-dependent decrease $(\mathrm{p}<0.05)$ only in the combinatorial regimens including AVCR and AVCRNP. However, $0.0005 \mathrm{mg} / \mathrm{kg}$ of CRNP (the quarter dose) induced the elevation of lymphocytes more than $0.00025 \mathrm{mg} / \mathrm{kg}$ of CRNP (the half dose), we observed a strange pattern in the case of CRNP, where the lymphocytes after the high dose of CRNP $(0.001 \mathrm{mg} / \mathrm{kg})$ administration was significantly decreased $(\mathrm{p}<0.001)$ compared to the half and the quarter doses and even the control. Furthermore, there were total leukocyte (WBCs) and granulocyte patterns of dose-dependent decreases $(p<0.05)$ after treatments with $\mathrm{AV}, \mathrm{AVNP}, \mathrm{CR}, \mathrm{CRNP}, \mathrm{AVCR}$, and AVCRNP as shown in Table 2.

Fig. $7 \mathrm{c}$ and $\mathrm{d}$ showed the hemostatic balance between platelets and the LP (the LPCR), where the platelets were decreased significantly $(\mathrm{p}<0.05)$ in blood (Fig. 7c), while the LPCR was elevated in the blood circulation (Fig. $7 \mathrm{~d}$ ). Table 3 showed that there were no dramatically changes of MPV, PDW, and PCT levels in the blood circulation when comparing the treated groups of the administrated therapeutic regimens with the control.

Fig. 7e illustrated that VEGF levels in rat sera were significantly decreased $(p<0.01)$ when comparing the treated groups with the control. We noticed that there was a significant dose-dependent increase $(p<0.05)$ of VEGF levels only in the individual regimens including $A V$, AVNP, CR, and CRNP, while there was a significant dosedependent decrease $(\mathrm{p}<0.05)$ only in the combinatorial regimens including AVCR and AVCRNP. 


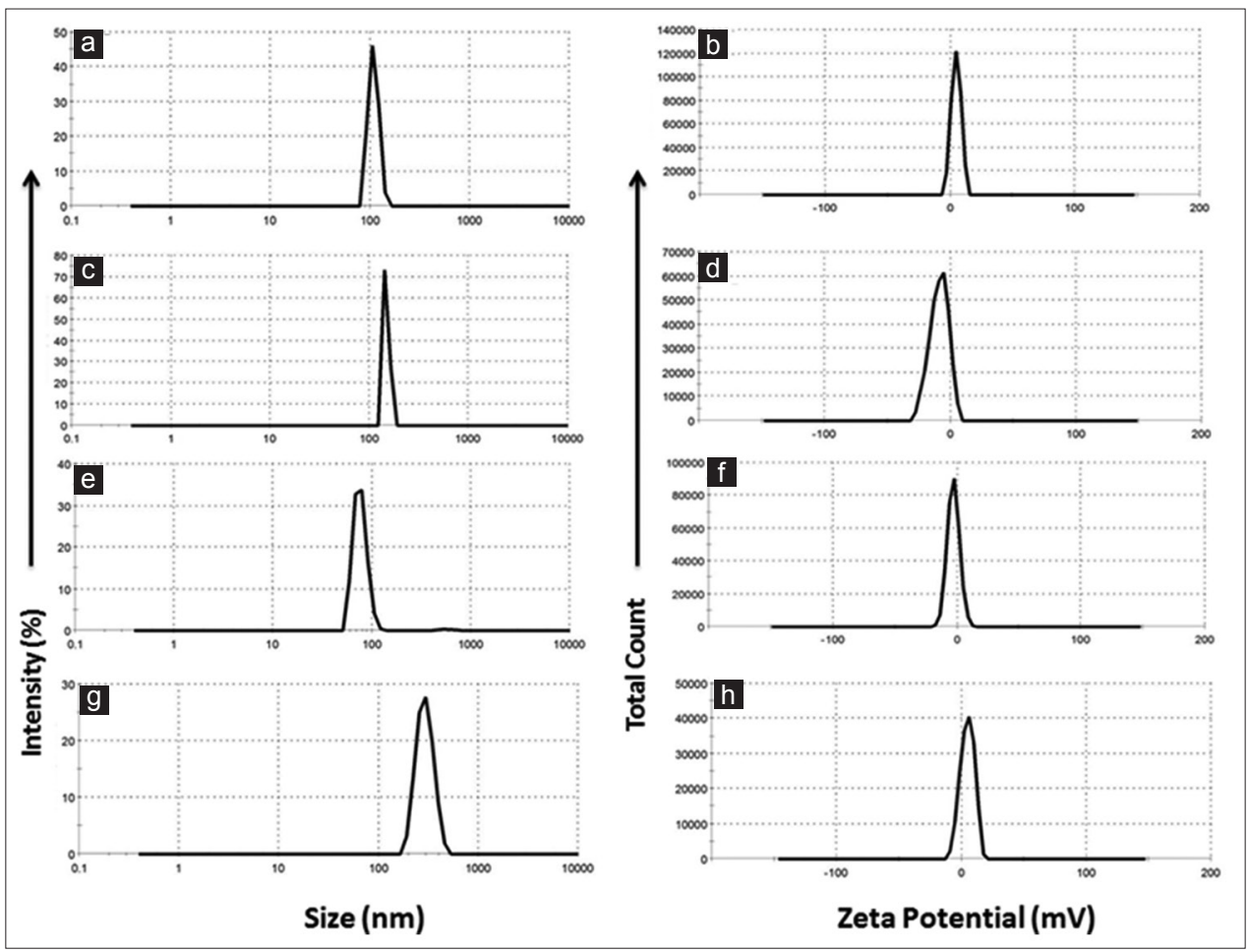

Fig. 3: Size distribution and apparent zeta potential. (a) Representative size distribution (108.9 $\mathrm{nm}$ ) of NV (F1) was drawn using Malvern ZetaSizer system based on PCS and laser diffractometry (LD). (b) Representative zeta potential (4.99 mV) of NV (F1) was drawn using Malvern ZetaSizer system based on PCS and LD. (c) Representative size distribution (147.8 nm) of AV nanoparticles (NPs) was drawn. (d) Representative zeta potential (-9.05 mV) of AVNPs was drawn. (e) Representative size distribution (76.26 nm) of CRNPs was drawn. (f) Representative zeta potential $(-2.81 \mathrm{mV})$ of AV NPs was drawn. (g) Representative size distribution (293.4 $\mathrm{nm}$ ) of AV-CRNPs was drawn. (h) Representative zeta potential $(4.71 \mathrm{mV})$ of AV-CRNPs was drawn

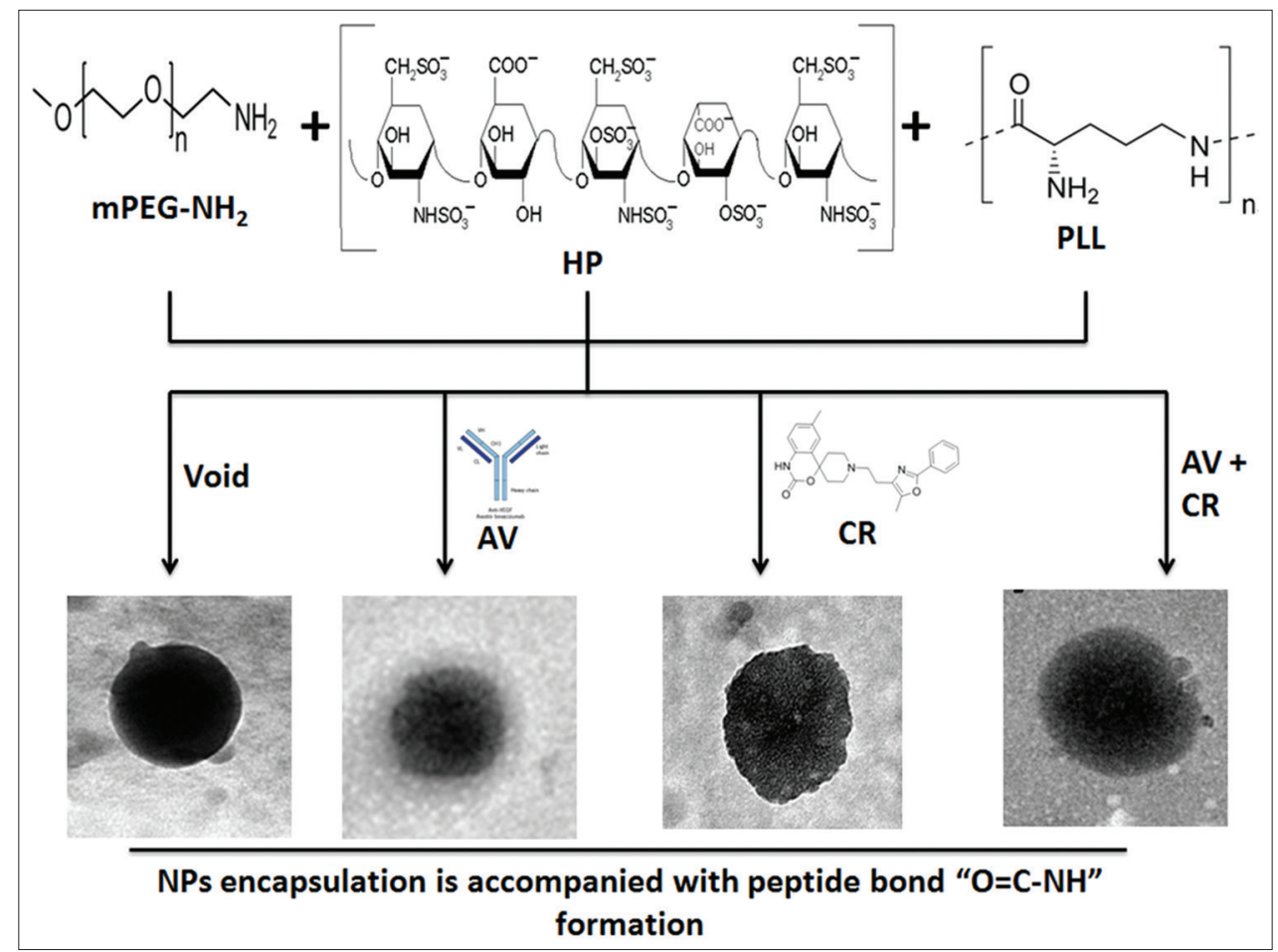

Fig. 4: Schematic diagram of nanoparticles encapsulation. To prepare PEG-HP- poly L-lysine (PLL) NPs, we first prepared the mixture of EDC and NHS. Then, NPs were produced by mixing the polymer with PLL phosphate buffer overnight at $4^{\circ} \mathrm{C}$. The mix ratio $(1: 6 \mathrm{v} / \mathrm{v}$, PLL: PEG-HP). NV, AVNPs, CRNPs, and AV-CRNPs encapsulation is accompanied with peptide bond " $\mathrm{O}=\mathrm{C}$-NH" formation

Histopathological alterations

The obtained tissue sections taken from the rat liver were stained by hematoxylin and eosin stains for investigation through the light electric microscope. Histopathological alterations were shown in Fig. 8. In control liver, there was no histopathological change, and the normal histological structure of the central vein and hepatocytes in the parenchyma were 


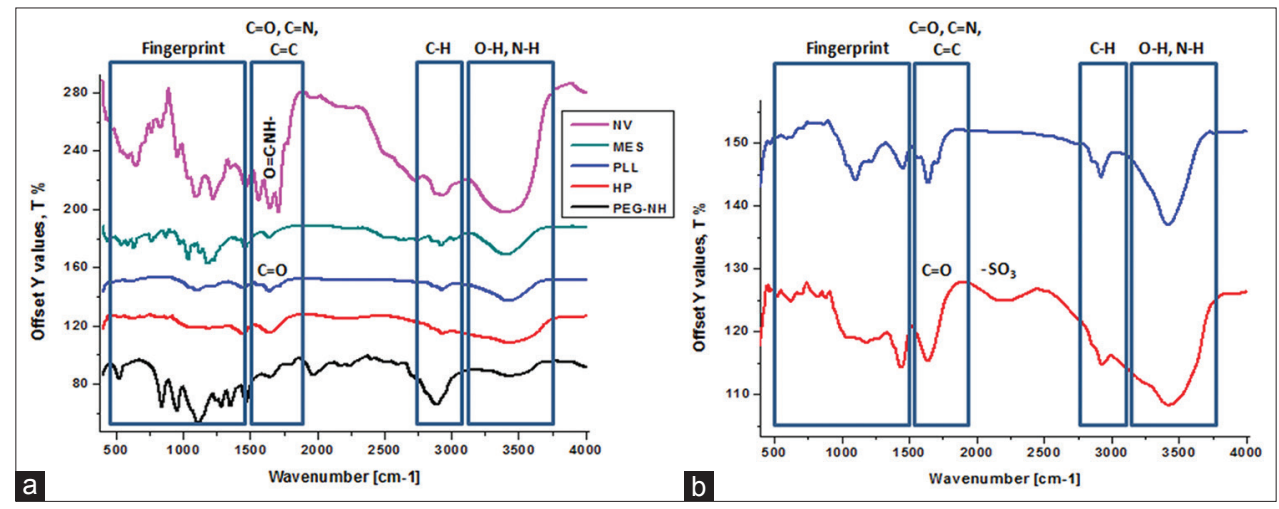

Fig. 5: (a) Fourier transform infrared spectroscopy (FTIR) of PEG-amine, heparin (HP), poly L-lysine (PLL), MES, and NVNPs was determined using Bruker Vector 22 FTIR. The spectra were obtained in the range of $500-4000 \mathrm{~cm}^{-1}$. NV encapsulation is accompanied with peptide bond "O=C-NH" formation and (b) the FTIR of HP and PLL were magnified to increase clarity

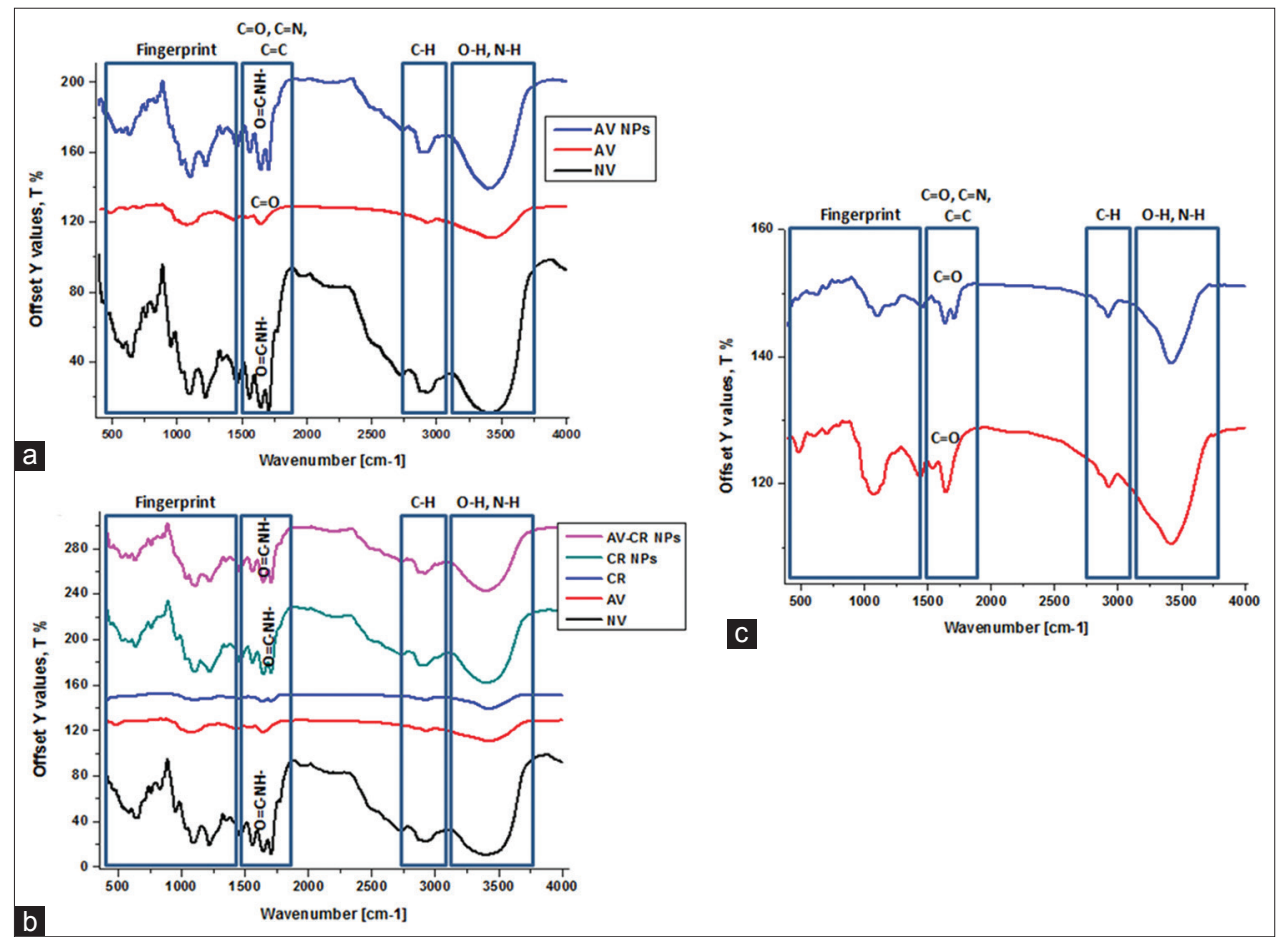

Fig. 6: (a) Fourier transform infrared spectroscopy (FTIR) of NVNPs, AV, and AVNPs was determined using Bruker Vector 22 FTIR. The spectra were obtained in the range of $500-4000 \mathrm{~cm}^{-1}$. NV encapsulation is accompanied with peptide bond " $\mathrm{O}=\mathrm{C}-\mathrm{NH}$ " formation. (b) The FTIR of NVNPs, AV, CR, CRNPs, and AV-CRNPs was determined. (c) The FTIR of AV and CR was magnified to increase clarity

recorded as shown in Fig. 8a. After AV administration with the high dose, the parenchyma showed focal necrosis with inflammatory cells infiltration associated with congestion in the central vein as well as the portal vein as shown in Fig. 8b. After AV administration with the quarter dose, focal necrosis with inflammatory cells infiltration was detected in the parenchyma associated with edema and inflammatory cells infiltration in the portal area as shown in Fig. 8c. After AVNP administration with the high dose, the portal area showed inflammatory cells infiltration, while the parenchyma had focal necrosis as shown in Fig. 8d. After AVNP administration with the quarter dose, the parenchyma showed focal necrosis associated with inflammatory cells infiltration in the portal area as shown in Fig. 8e. After CR administration with the high dose, massive inflammatory cells infiltration was detected in the portal area as shown in Fig. 8f. After CR administration with the quarter dose, the portal area showed focal inflammatory cells aggregation as well as diffuses inflammatory cells infiltration in the others with congestion in the portal vein as shown in Fig. 8g. After CRNP administration with the high dose, periductal fibrosis with inflammatory cells infiltration was detected surrounding the bile ducts at the portal area with congestion in the portal vein as shown in Fig. 8h. After CRNP administration with the quarter dose, the portal area showed massive inflammatory cells infiltration as well as focal inflammatory cells aggregation in the parenchyma as shown in Fig. 8i. After AVCRNP administration with the high dose, massive inflammatory cells infiltration was detected in the portal area as shown in Fig. 8j.

Leukocyte migration process involves multi-steps and regulates the presence of immune cells throughout the human being's body. In normal noninflammatory circumstances, homeostatic chemokines are supposed to adjust the transmission of hematopoietic cells intermediate - between blood and tissues. Inflammation induces changes in the cellular compositions of these sites, with quicker infiltration of immune cells from the bone marrow to the circulation [27].

The infiltration of the circulating immune cells into tissues is supposed to be driven by connections between chemokine receptors (example: CCR2) 


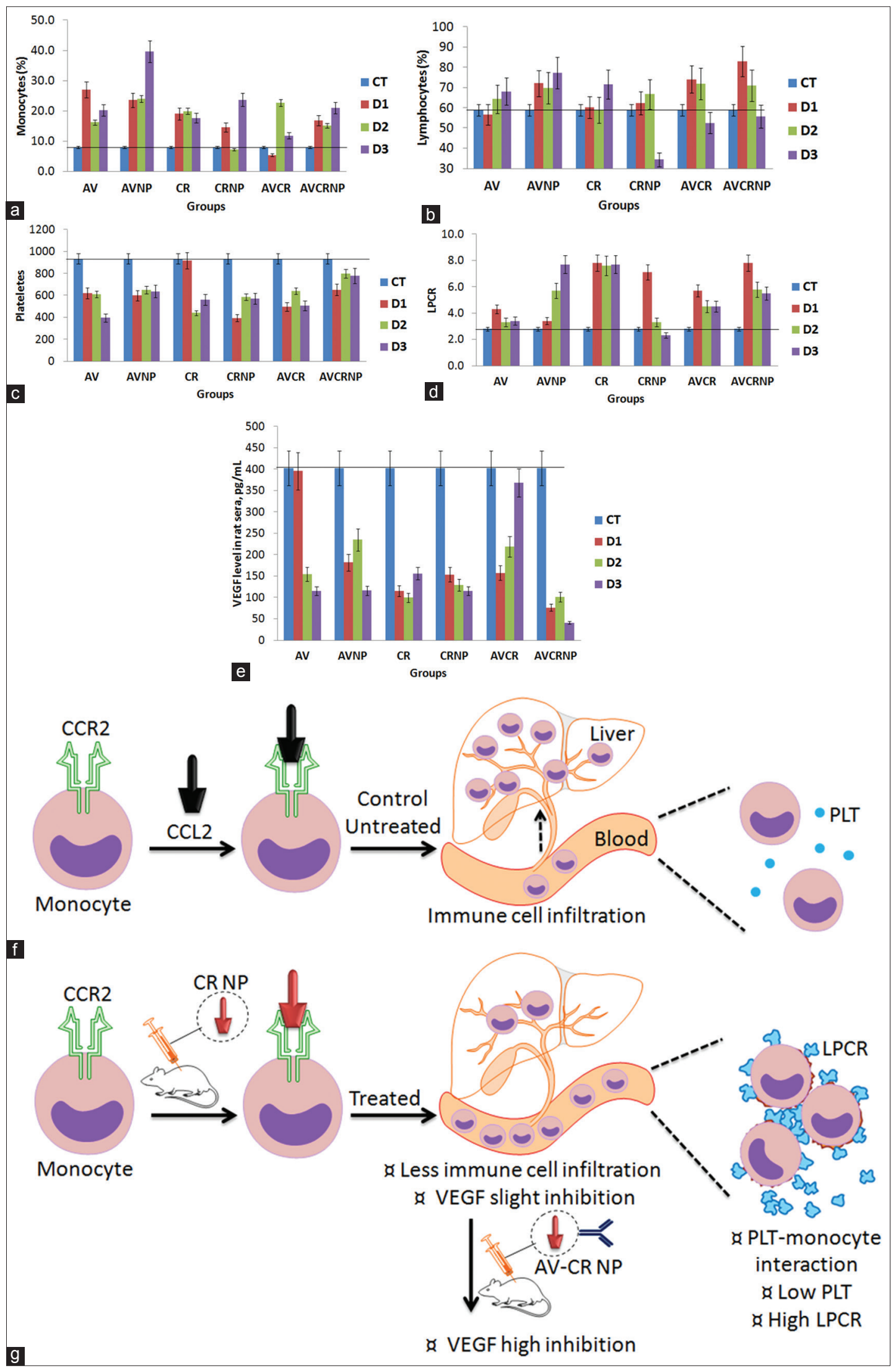

Fig. 7: The mechanism of the action of immunomodulation after AV, AVNP, CR, CRNP, AVCR, and AVCRNP administrations in vivo. Monocytes (a) and lymphocytes (b) were significantly accumulated in blood after treatments with AV, AVNP, CR, CRNP, AVCR, and AVCRNP. Platelets were decreased in blood (c), while the LP (the LPCR) was elevated in the blood circulation (d). (e) VEGF levels in rat sera were significantly decreased when comparing the treated groups with the control. ( $f$ and $g$ ) Schematic diagrams of the mechanism of action of immunomodulation after $\mathrm{AV}$ and $\mathrm{CR}$ regimens administrations in rats (g) compared to the control (f) 
Table 2: WBCs and granulocytes measurements after the dose-dependent manner of the administrated therapeutic regimens

\begin{tabular}{|c|c|c|c|c|c|}
\hline \multirow[t]{2}{*}{ Parameters } & \multirow[t]{2}{*}{ Groups } & CT & D1 & D2 & D3 \\
\hline & & Mean \pm SD & Mean \pm SD & Mean \pm SD & Mean \pm SD \\
\hline \multirow[t]{5}{*}{ WBCs } & $\mathrm{AV}$ & $11.8 \pm 1.01$ & $7.4 \pm 0.62$ & $9 \pm 0.75$ & $6.3 \pm 0.57$ \\
\hline & $\mathrm{CR}$ & $11.8 \pm 1.01$ & $9.5 \pm 0.79$ & $11.2 \pm 0.93$ & $11.3 \pm 1.03$ \\
\hline & CRNP & $11.8 \pm 1.01$ & $6.9 \pm 0.58$ & $14.2 \pm 1.18$ & $23.5 \pm 2.14$ \\
\hline & AVCR & $11.8 \pm 1.01$ & $7.6 \pm 0.63$ & $11.4 \pm 0.95$ & $13.0 \pm 1.18$ \\
\hline & AVCRNP & $11.8 \pm 1.01$ & $8.8 \pm 0.73$ & $7.8 \pm 0.65$ & $10.6 \pm 0.96$ \\
\hline \multirow[t]{6}{*}{ Granulocytes (\%) } & $\mathrm{AV}$ & $33.1 \pm 2.83$ & $16.3 \pm 1.36$ & $19.5 \pm 1.63$ & $11.7 \pm 1.06$ \\
\hline & AVNP & $33.1 \pm 2.83$ & $17.8 \pm 1.48$ & $17.4 \pm 1.45$ & $16.3 \pm 1.48$ \\
\hline & CR & $33.1 \pm 2.83$ & $20.8 \pm 1.73$ & $21.3 \pm 1.78$ & $10.8 \pm 0.98$ \\
\hline & CRNP & $33.1 \pm 2.83$ & $20 \pm 1.67$ & $26.8 \pm 2.23$ & $57.2 \pm 5.20$ \\
\hline & AVCR & $33.1 \pm 2.83$ & $11.4 \pm 0.95$ & $15.5 \pm 1.29$ & $40.3 \pm 3.66$ \\
\hline & AVCRNP & $33.1 \pm 2.83$ & $15.4 \pm 1.28$ & $15.6 \pm 1.30$ & $20.7 \pm 1.88$ \\
\hline
\end{tabular}

Table 3: MPV, PDW, and PCT measurements after the dose-dependent manner of the administrated therapeutic regimens

\begin{tabular}{llllll}
\hline \multirow{2}{*}{ Parameters } & Groups & CT & D1 & D2 & D3 \\
\cline { 3 - 6 } & & Mean \pm SD & Mean \pm SD & Mean \pm SD & Mean \pm SD \\
\hline MPV & AV & $5.7 \pm 0.49$ & $6.1 \pm 0.51$ & $5.6 \pm 0.47$ & $5.9 \pm 0.54$ \\
& AVNP & $5.7 \pm 0.49$ & $5.7 \pm 0.48$ & $6.5 \pm 0.54$ & $6.6 \pm 0.60$ \\
& CR & $5.7 \pm 0.49$ & $6.8 \pm 0.57$ & $6.5 \pm 0.54$ & $6.6 \pm 0.60$ \\
CRNP & $5.7 \pm 0.49$ & $5.7 \pm 0.48$ & $5.5 \pm 0.46$ & $6 \pm 0.55$ \\
PDW & AVCR & $5.7 \pm 0.49$ & $6.3 \pm 0.53$ & $6.1 \pm 0.51$ & $6.1 \pm 0.55$ \\
& AVCRNP & $5.7 \pm 0.49$ & $6.7 \pm 0.56$ & $6.3 \pm 0.53$ & $6.3 \pm 0.57$ \\
& AV & $8.8 \pm 0.75$ & $6.2 \pm 0.52$ & $8.6 \pm 0.72$ & $9.1 \pm 0.83$ \\
& AVNP & $8.8 \pm 0.75$ & $8.8 \pm 0.73$ & $9.8 \pm 0.82$ & $9.9 \pm 0.90$ \\
& CR & $8.8 \pm 0.75$ & $10 \pm 0.83$ & $9.8 \pm 0.82$ & $9.9 \pm 0.90$ \\
CRNP & $8.8 \pm 0.75$ & $8.7 \pm 0.73$ & $8.6 \pm 0.72$ & $9.1 \pm 0.83$ \\
PCT & AVCR & $8.8 \pm 0.75$ & $9.4 \pm 0.78$ & $9.3 \pm 0.78$ & $9.2 \pm 0.84$ \\
& AVCRNP & $8.8 \pm 0.75$ & $9.9 \pm 0.83$ & $9.4 \pm 0.78$ & $9.5 \pm 0.86$ \\
& AV & $0.54 \pm 0.05$ & $0.38 \pm 0.03$ & $0.34 \pm 0.03$ & $0.23 \pm 0.02$ \\
& AVNP & $0.54 \pm 0.05$ & $0.34 \pm 0.03$ & $0.42 \pm 0.04$ & $0.42 \pm 0.04$ \\
& CR & $0.54 \pm 0.05$ & $0.62 \pm 0.05$ & $0.28 \pm 0.02$ & $0.37 \pm 0.03$ \\
& CRNP & $0.54 \pm 0.05$ & $0.21 \pm 0.02$ & $0.42 \pm 0.04$ & $0.53 \pm 0.05$ \\
& AVCR & $0.54 \pm 0.05$ & $0.31 \pm 0.03$ & $0.39 \pm 0.03$ & $0.30 \pm 0.03$ \\
& AVCRNP & $0.54 \pm 0.05$ & $0.54 \pm 0.05$ & $0.60 \pm 0.05$ & $0.63 \pm 0.06$ \\
\hline
\end{tabular}

and their ligands (example: CCL2) [28]. CCR2 has been allied with the recruitment of monocytes and/or lymphocytes from the circulation to the target sites $[29,30]$. Herein, we have examined the effect of CCR2 antagonist on monocyte and lymphocytes relocation. Our results have designated that CCR2-CCR2 antagonist interactions were blocked the infiltration of monocytes from the blood, resulting in an accumulation of these types of immune cells in the circulation, as we observed in the results (Fig. 7g). This observation is in agreement with a previous study [31]. For more clarification of that point, it was validated that the lack of CCR2 changed the shape of circulating monocytes recommending that reduced inflammation may consequence from diminished inflammatory monocyte rates in the circulation rather than from reduced staffing of monocytes from the circulation into tissues [31]. Monocyte relocation from the circulation to the organ and succeeding relocation toward $\mathrm{T}$ cell parts of the white pulp might encompass the consecutive arrangement of numerous chemokines separate from CCR2 [32,33].

Basically, CCL2 is secreted in response to inflammation [34]. In normal conditions, low secretion of CCL2 induces the homeostatic relocation of inflammatory monocytes from bone marrow into the bloodstream [31]. For example, infection with Listeria monocytogenes persuades CCL2 secretion in the spleen and the blood circulation [35].

A considerable number of clinical surveys emphasized that inflammation contributes greatly in tumor formation [36]. The crosstalk between tumor cells and the tumor-infiltrating cells is also shown recently as a significant contributor in cancer development, drug resistance, and cancer invasion. For example, CCL2, secreted by numerous tumors, mediates immunoinhibitory effects and facilitates tumor metastasis. Blocking of CCL2-CCR2 signaling using CCR2 antagonist, as studied here in the current study, can be further used to boost CD8+ T-cellmediated responses and inhibit metastasis [37].

However, even though angiogenesis is the communal leading cause of tumor progression, abruptly targeting the crucial contributing factor, VEGF, is still risky. Based on the assumption that tumor mass consists of multigenotypic population, the VEGF-targeting therapy (i.e. AV) may select for the adapting tumor cells [38]. According to previous results from human cancer studies, anti-VEGF therapy usually results in regrowth of clonal populations with the characteristics of expressing higher compensatory factors such as VEGF, fibroblast growth factor, and platelet-derived growth factor [38], so we used AV in combination with CCR2 antagonist (CR) to inhibit VEGF and block the CCR2-CCL2 signaling network that may be used as a promising anticancer therapeutic regimen in further studies.

It was suggested that nano-formulation of chemotherapies increases their targetability and stability in addition to reduces adverse effects of them and provides adequate drug delivery approach [18-21]. Recently, several delivery systems were developed by utilizing pegylation process [39], which increased the half-life and activity of drugs, and reduced liver toxicity in mice, thus allowing the drug dosages to be reduced [40]. NPs have been great predestined as carriers for the delivery of drugs due to their small size, and sustained-release characteristics $[41,42]$.

In the current study, we used PEG and PLL for synthesizing the AV, CR, and AV-CR NPs. PLL has a benefit of being hydrodegradable, biodegradable, and biocompatible [43], and so it is appropriate for the backbone as a drug delivery transporter. Recently, it has been reported that PLL-modified poly (lactic-co-glycolic acid) (PLGA) NPs presented significantly higher quantities than unmodified PLGA NPs [44]. Therefore, in this work, we selected PLL and PEG for encapsulating AV and CCR2 antagonist (CR) to achieve bioavailable and biocompatible NPs, as well as the sustained release of these drugs.

Our AV PEG-PLL NPs noted high encapsulation efficiency (EE =86\%) of $\mathrm{AV}$ with high stability based on the zeta potential negative charges $(-9.05+1.2)$ reported on the surface of the synthesized AVNPs, then TEM images came to confirm its uniformity and z-average diameter came to confirm that it is in the nano-range $(147.8+3.4)$ and PDI of 0.01 . On the contrary, the authors in a previous study [45] found that a higher loading of $\mathrm{AV}$, the PLGA particles lost its uniform, this was most likely due to fractional phase parting of PLGA polymer and AV.

When authors added PEG to their NPs (PEG-PLGA), it is supposed that the NPs produced from this polymer are long-circulating within the in vivo model, because PEG is widely used as a graft-forming polymer in addition to the release rate of the loaded therapeutic molecule. 


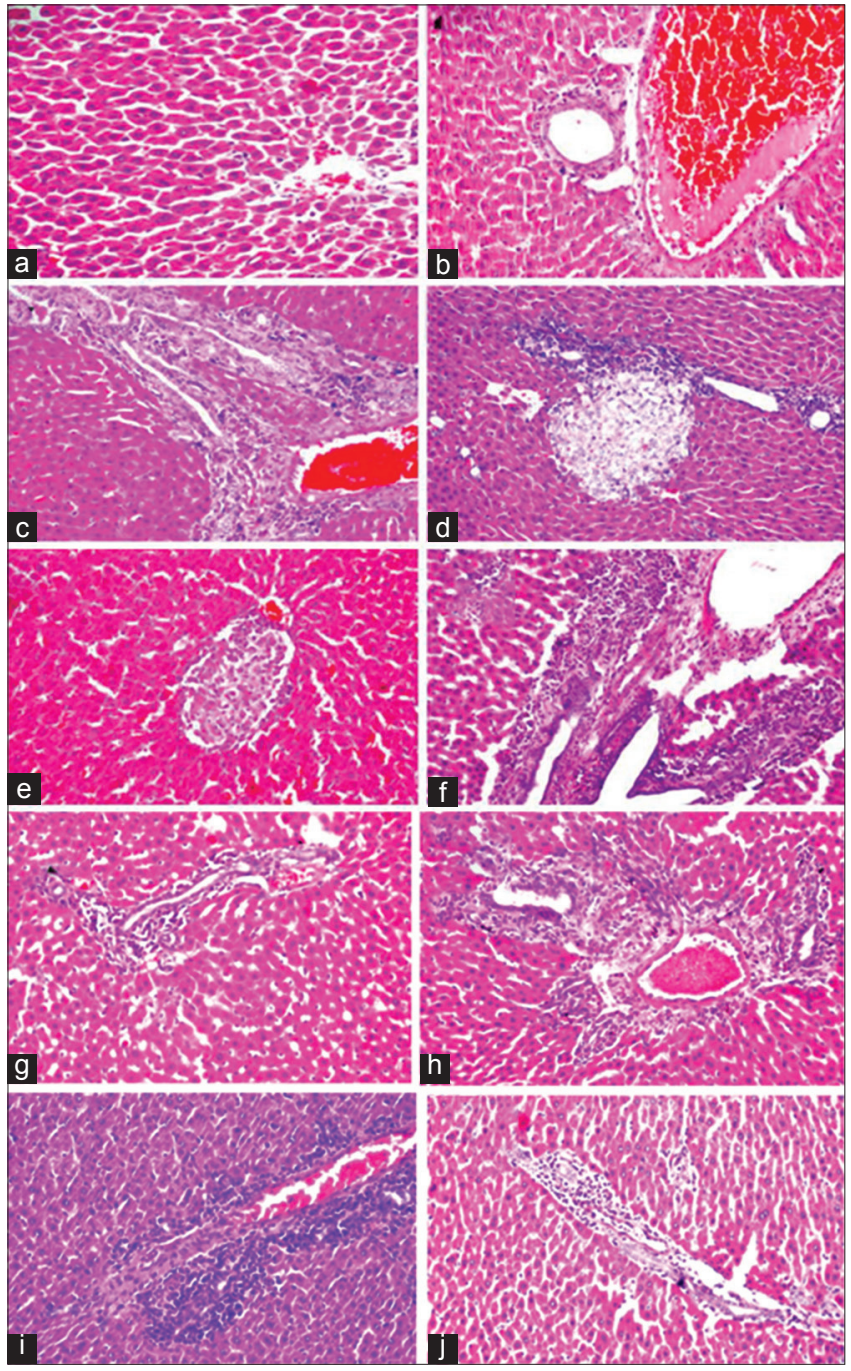

Fig. 8: Histopathological alteration. (a) Control liver,

(b) liver after AV administration with the high dose, (c)

liver after $\mathrm{AV}$ administration with the quarter dose, (d)

liver after AVNP administration with the high dose, (e) liver after AVNP administration with the quarter dose, (f) liver after CR administration with the high dose, (g) liver after

CR administration with the quarter dose, (h) liver after

CRNP administration with the high dose, (i) liver after CRNP administration with the quarter dose, and (j) liver after AVCRNP administration with the high dose

Unlike PLGA, the hydrophilicity of PEG also facilitated dispensing the particles [45]. These results are in agreement of our PEG-PLL based NPs.

It is suggested that the use of liposomes was stated for augmenting the in vivo residence of $\mathrm{AV}$ in in vivo model [46]. However, the described drug EE was only about $45 \%$. Hao et al. [47] also conveyed a similar drug EE using ethyl acetate and phosphate solution. However, in our method, the EE of the AV PEG-PLL NPs recorded (86\%), which is a bit similar to Li's PLGA-PEG drug EE (90\%), which was achieved through double emulsion method [45].

The problem of AV PLGA NPs is that after a certain time period, the PLGA instigated degrading and released additional drug entrapped in the polymeric base [48], so it is not stable such as our synthesized AV PEG-PLL NPs.

In a previous study, PEG-grafted chitosan NPs were synthesized [49]. As FTIR technique was investigated in the current study, they also performed the same techniques and indicated that the nonexistence of peaks at $1774 \mathrm{~cm}^{-1}$ and $1710 \mathrm{~cm}^{-1}$ in their NPs confirm the complete dissociation of phthalimido group from chitosan and the entrance of peaks $1633 \mathrm{~cm}^{-1}$ (amide I) and $1582 \mathrm{~cm}^{-1}$ (amide II) corresponds to the attendance of primary amine groups in chitosan. The peak at $2871 \mathrm{~cm}^{-1}$ refers to the attendance of PEG, which a little bit similar to our FTIR results.

CCL2 was proved to recruit the monocytes into the area of dynamic inflammation. In this term, it was found that the inspiration of RANTES leads to staffing of monocytes/lymphocytes [50,51]. Apart from employing leukocyte movement, many lines of signals indicate that CCL2 might affect T-immunity. First, CCL2 upregulation is linked with the progress of polarized $\mathrm{Th}_{2}$ responses [52], and CCL2 improves the emission of IL- 4 by $\mathrm{T}$ cells [53]. Second, in $\mathrm{Th}_{2}$ immune-mediated diseases, such as asthma, CCL2 is expressed at high levels, and its neutralization in animal models ameliorates disease [54]. Finally, other chemokines and their receptors are linked to specific responses of T-helper cells [55]. These findings provide an important clue in the current study as to why when we blocked the CCR2-CCL2 signaling pathway the monocytes and lymphocytes were not infiltrated and then accumulated in the circulation.

This may be critical for the effective directive of the immune reply to cancer and viral infection for further studies. For example, $\mathrm{Th}_{1}$ and $\mathrm{Th}_{2}$ cells, due to their dissimilar chemokine receptor expression design induced by CCL2, are likely to have dissimilar susceptibility to viral infection [53].

Chemokines are elaborate in normal activities in the host that affect tumor; hence, it is probable that they will be existing to have important impacts on different cancers. For this reason, chemokines might be predictable to have growth regulating effects on cancer cells depending on the specific setting in which they are found. Further, due to their ability to attract lymphocytes, some chemokines might be predicted to activate host antitumor replies. On the other hand, certain chemokines are known to have angiogenic properties, which could relate to tumor progression [56]. CCL2 expression in tumor cells is significantly connected with the extent of tumor-associated-macrophage (TAM) penetration [57], and in particular, both CCL2 and VEGF expressions were positively linked with TAM infiltration, angiogenesis, and then poor cancer survival [58].

The observations presented in a previous study [59] indicated that activated platelet interactions with the monocytes promote the inducible form of cyclooxygenase (COX-2) expression and augmented prostaglandin E2 (PGE2) synthesis by monocytes by methods concerning cellular adhesion and in response induced cytokine pathways. Rapid binding of P-select in on the plasma membranes of triggered platelets to the monocytes mediates stable communication between the 2 cell types [60]. Moreover, monocytes adhesion to P-select modulates the protein and gene expression of COX-2. A similar design was described for some transcripts in models of monocyte gene expression induced by adhesion to matrix structures by surface integrins [61]. A second signal is then delivered by IL-1 $\beta$ in response to the cellular communication. Thus, regulation of COX-2 expression may exist at both transcriptional and post-transcriptional levels, consisting with the COX-2 enzyme as a highly regulated gene [62]. Unregulation of COX-2 may affect inflammatory response together with interpretations that platelet activation and platelet-leukocyte aggregation are frequently linked with these ailments [63-66].

Integrative pathways of COX-2 protein synthesis are associated with monocytes response to different signals and related to activated platelets which regulate through COX-2 gene in a specialized cellular process. This way of control may evolve for a controlled inflammatory response and here we can discuss the results summarized in Fig. $7 \mathrm{f}$ and g, when we blocked the CCR2 expressed on the immune cells (example: Monocytes) using the CCR2 antagonist (CR) in their free and 
nanoformulations that lead to lowering of immune cell infiltration from the circulation. Providing AV to CR in their free and nanoformulations significantly inhibited VEGF. Eventually, the accumulation of monocytes in the circulating blood leads to platelet (PLT)-monocyte interaction with the aggregation of the PLT in the form of LPCR (Fig. 7g).

\section{ACKNOWLEDGMENTS}

The authors would like to thank the principal investigator Dr. Ahmed A. Abd-Rabou for providing support by the National Research Centre Grant (No: 11010333).

\section{ETHICS}

The study protocol followed the guidelines approved by the Ethical Committee of the Medical Research of the National Research Centre (Approval No. 16/281).

\section{AUTHORS' CONTRIBUTIONS}

Abd-Rabou AA contributed in gaining fund, hypothesizing the manuscript idea, practical work, data analysis, manuscript writing, and manuscript reviewing. Ahmed HH contributed in practical work, data analysis, manuscript writing, and manuscript reviewing. Kishta MS contributed in hypothesizing the manuscript idea, practical work, and manuscript reviewing.

\section{CONFLICTS OF INTEREST}

The authors report no conflicts of interest.

\section{REFERENCES}

1. Rollins BJ. Chemokines. Blood 1997;90:909-28.

2. Deshmane SL, Kremlev S, Amini S, Sawaya BE. Monocyte chemoattractant protein-1 (MCP-1): An overview. J Interferon Cytokine Res 2009;29:313-26.

3. Bachelerie F, Ben-Baruch A, Burkhardt AM, Combadiere C, Farber JM, Graham GJ, et al. International union of basic and clinical pharmacology. [corrected]. LXXXIX. Update on the extended family of chemokine receptors and introducing a new nomenclature for atypical chemokine receptors. Pharmacol Rev 2014;66:1-79.

4. Charo IF, Myers SJ, Herman A, Franci C, Connolly AJ, Coughlin SR, et al. Molecular cloning and functional expression of two monocyte chemoattractant protein 1 receptors reveals alternative splicing of the carboxyl-terminal tails. Proc Natl Acad Sci U S A 1994;91:2752-6.

5. Zhang T, Somasundaram R, Berencsi K, Caputo L, Gimotty P, Rani P, et al. Migration of cytotoxic $\mathrm{T}$ lymphocytes toward melanoma cells in three-dimensional organotypic culture is dependent on CCL2 and CCR4. Eur J Immunol 2006;36:457-67.

6. Rossi D, Zlotnik A. The biology of chemokines and their receptors. Annu Rev Immunol 2000;18:217-42.

7. Shi C, Pamer EG. Monocyte recruitment during infection and inflammation. Nat Rev Immunol 2011;11:762-74.

8. Torres S, Bartolomé RA, Mendes M, Barderas R, Fernandez-Aceñero MJ, Peláez-García A, et al. Proteome profiling of cancer-associated fibroblasts identifies novel proinflammatory signatures and prognostic markers for colorectal cancer. Clin Cancer Res 2013;19:6006-19.

9. Lu B, Rutledge BJ, Gu L, Fiorillo J, Lukacs NW, Kunkel SL, et al. Abnormalities in monocyte recruitment and cytokine expression in monocyte chemoattractant protein 1-deficient mice. J Exp Med 1998;187:601-8.

10. Boring L, Gosling J, Chensue SW, Kunkel SL, Farese RV Jr., Broxmeyer HE, et al. Impaired monocyte migration and reduced Type 1 (Th1) cytokine responses in C-C chemokine receptor 2 knockout mice. J Clin Invest 1997;100:2552-61.

11. Geissmann F, Jung S, Littman DR. Blood monocytes consist of two principal subsets with distinct migratory properties. Immunity 2003;19:71-82.

12. Luther SA, Cyster JG. Chemokines as regulators of T cell differentiation. Nat Immunol 2001;2:102-7.

13. Roca H, Varsos Z, Pienta KJ. CCL2 protects prostate cancer PC3 cells from autophagic death via phosphatidylinositol 3-kinase/AKTdependent survivin up-regulation. J Biol Chem 2008;283:25057-73.

14. Loberg RD, Ying C, Craig M, Yan L, Snyder LA, Pienta KJ, et al. CCL2 as an important mediator of prostate cancer growth in vivo through the regulation of macrophage infiltration. Neoplasia 2007;9:556-62.

15. Lim SY, Raftery MJ, Goyette J, Hsu K, Geczy CL. Oxidative modifications of S100 proteins: Functional regulation by redox. J Leukoc Biol 2009;86:577-87.

16. Tong RT, Boucher Y, Kozin SV, Winkler F, Hicklin DJ, Jain RK, et al. Vascular normalization by vascular endothelial growth factor receptor 2 blockade induces a pressure gradient across the vasculature and improves drug penetration in tumors. Cancer Res 2004;64:3731-6.

17. Hijaz M, Das S, Mert I, Gupta A, Al-Wahab Z, Tebbe C, et al. Folic acid tagged nanoceria as a novel therapeutic agent in ovarian cancer. BMC Cancer 2016;16:220.

18. Abd-Rabou AA, Bharali DJ, Mousa SA. Taribavirin and 5-fluorouracilloaded pegylated-lipid nanoparticle synthesis, p38 docking, and antiproliferative effects on MCF-7 breast cancer. Pharm Res 2018;35:76.

19. Abd-Rabou AA, Ahmed HH. CS-PEG decorated PLGA nano-prototype for delivery of bioactive compounds: A novel approach for induction of apoptosis in hepG2 cell line. Adv Med Sci 2017;62:357-67.

20. Abd-Rabou AA,Abdalla AM, Ali NA, Zoheir KM. Moringa oleifera root induces cancer apoptosis more effectively than leave nanocomposites and its free counterpart. Asian Pac J Cancer Prev 2017;18:2141-9.

21. Shalby AB, Abd-Rabou AA, Ahmed HH. Nano-Se cross talks with nano-DOX/FU to selectively hack hepatic cancer cells and spare normal cells healthy: A mechanism-based study. J Appl Pharm Sci 2017;7:3-12.

22. Chae SY, Kim TH, Park K, Jin CH, Son S, Lee S, et al. Improved antitumor activity and tumor targeting of $\mathrm{NH}(2)$-terminal-specific PEGylated tumor necrosis factor-related apoptosis-inducing ligand. Mol Cancer Ther 2010;9:1719-29.

23. Panyam J, Labhasetwar V. Biodegradable nanoparticles for drug and gene delivery to cells and tissue. Adv Drug Deliv Rev 2003;55:329-47.

24. Lim SM, Kim TH, Jiang HH, Park CW, Lee S, Chen X, et al. Improved biological half-life and anti-tumor activity of TNF-related apoptosis-inducing ligand (TRAIL) using PEG-exposed nanoparticles. Biomaterials 2011;32:3538-46.

25. A.O.A.C. Official Methods of Analysis. $16^{\text {th }}$ ed. Washington, DC: Association of Official Analysis; 1995.

26. Banchroft JD, Stevens A, Turner DR. Theory and Practice of Histological Techniques. $4^{\text {th }}$ ed. New York, London, San Francisco, Tokyo: Churchill Livingstone; 1996.

27. Ueda Y, Yang K, Foster SJ, Kondo M, Kelsoe G. Inflammation controls B lymphopoiesis by regulating chemokine CXCL12 expression. J Exp Med 2004;199:47-58.

28. Rot A, von Andrian UH. Chemokines in innate and adaptive host defense: Basic chemokinese grammar for immune cells. Annu Rev Immunol 2004;22:891-928.

29. Kurihara T, Warr G, Loy J, Bravo R. Defects in macrophage recruitment and host defense in mice lacking the CCR2 chemokine receptor. J Exp Med 1997:186:1757-62

30. Serbina NV, Salazar-Mather TP, Biron CA, Kuziel WA, Pamer EG. TNF/iNOS-producing dendritic cells mediate innate immune defense against bacterial infection. Immunity 2003;19:59-70.

31. Serbina NV, Pamer EG. Monocyte emigration from bone marrow during bacterial infection requires signals mediated by chemokine receptor CCR2. Nat Immunol 2006;7:311-7.

32. Ansel KM, Ngo VN, Hyman PL, Luther SA, Förster R, Sedgwick JD, et al. A chemokine-driven positive feedback loop organizes lymphoid follicles. Nature 2000;406:309-14.

33. Reif K, Ekland EH, Ohl L, Nakano H, Lipp M, Förster R, et al. Balanced responsiveness to chemoattractants from adjacent zones determines B-cell position. Nature 2002;416:94-9.

34. Wood S, Jayaraman V, Huelsmann EJ, Bonish B, Burgad D, Sivaramakrishnan G, et al. Pro-Inflammatory Chemokine CCL2 (MCP-1) Promotes Healing in Diabetic Wounds by Restoring the Macrophage Response. PLoS ONE 2014; 9(3): Avaliable from. https:// doi.org/10.1371/journal.pone.0091574

35. Auerbuch V, Brockstedt DG, Meyer-Morse N, O'Riordan M, Portnoy DA. Mice lacking the Type I interferon receptor are resistant to listeria monocytogenes. J Exp Med 2004;200:527-33.

36. Korniluk A, Koper O, Kemona H, Dymicka-Piekarska V. From inflammation to cancer. Ir J Med Sci 2017;186:57-62.

37. Qian BZ, Li J, Zhang H, Kitamura T, Zhang J, Campion LR, et al. CCL2 recruits inflammatory monocytes to facilitate breast-tumour metastasis. Nature 2011;475:222-5.

38. Bottsford-Miller JN, Coleman RL, Sood AK. Resistance and escape from antiangiogenesis therapy: Clinical implications and future strategies. J Clin Oncol 2012;30:4026-34

39. Verhoef JJF, Anchordoquy TJ. Questioning the Use of PEGylation for Drug Delivery. Drug Deliv Transl Res 2013;3:499-503. 
40. Knop K, Hoogenboom R, Fischer D, Schubert US. Poly (ethylene glycol) in drug delivery: pros and cons as well as potential alternatives. Angew. Chem. Int. Ed 2010;49:6288-6308

41. Petros RA, DeSimone JM. Strategies in the design of nanoparticles for therapeutic applications. Nat Rev Drug Discov 2010;9:615-27.

42. Geels P, Eisenhauer E, Bezjak A, Zee B, Day A. Palliative effect of chemotherapy: Objective tumor response is associated with symptom improvement in patients with metastatic breast cancer. J Clin Oncol 2000; $18: 2395-405$

43. Umano M, Uechi K, Uriuda T, Murayama S, Azuma H, Shinohara A, et al. Tumor accumulation of $\varepsilon$-poly-lysines-based polyamines conjugated with boron clusters. Appl Radiat Isot 2011;69:1765-7.

44. Tahara K, Furukawa S, Yamamoto H, Kawashima Y. Hybrid-modified poly(D,L-lactide-co-glycolide) nanospheres for a novel cellular drug delivery system. Int J Pharm 2010;392:311-3.

45. Li F, Hurley B, Liu Y, Leonard B, Griffith M. Controlled release of bevacizumab through nanospheres for extended treatment of agerelated macular degeneration. Open Ophthalmol J 2012;6:54-8.

46. Abrishami M, Zarei-Ghanavati S, Soroush D, Rouhbakhsh M, Jaafari MR, Malaekeh-Nikouei B, et al. Preparation, characterization, and in vivo evaluation of nanoliposomes-encapsulated bevacizumab (avastin) for intravitreal administration. Retina 2009;29:699-703.

47. Hao Y, Patel A, Liu W, Krishna R, Sabates NR, Mitra AK. Preparation and Characterization of Bevacizumab (Avastin) Nanoparticles for the Treatment of Age Related Macular Degeneration. Los Angeles, California, U.S.A: American Association of Pharmaceutical Scientists (AAPS) Annual Meeting and Exposition; 2009. Available from: http:// www.aapsj.org/abstracts/AM 2009/AAPS2009-002539.PDF.

48. Cao X, Schoichet MS. Delivering neuroactive molecules from biodegradable microspheres for application in central nervous system disorders. Biomaterials 1999;20:329-39.

49. Malhotra M, Lane C, Tomaro-Duchesneau C, Saha S, Prakash S. A novel method for synthesizing PEGylated chitosan nanoparticles: Strategy, preparation, and in vitro analysis. Int J Nanomedicine 2011;6:485-94.

50. Brown Z, Robson RL, Westwick J. Regulation and expression of chemokines: Potential role in glomerulonephritis. J Leukoc Biol 1996;59:75-80.

51. Haberstroh U, Stilo K, Pocock J, Wolf G, Helmchen U, Wenzel U, et al. L-arginine suppresses lipopolysaccharide-induced expression of RANTES in glomeruli. J Am Soc Nephrol 1998;9:203-10.

52. Handel TM, Domaille PJ. Heteronuclear $(1 \mathrm{H}, 13 \mathrm{C}, 15 \mathrm{~N})$ NMR assignments and solution structure of the monocyte chemoattractant protein-1 (MCP-1) dimer. Biochemistry 1996;35:6569-84

53. Karpus WJ, Lukacs NW, Kennedy KJ, Smith WS, Hurst SD, Barrett TA, et al. Differential CC chemokine-induced enhancement of T helper cell cytokine production. J Immunol 1997;158:4129-36.

54. Gonzalo JA, Lloyd CM, Wen D, Albar JP, Wells TN, Proudfoot A, et al. The coordinated action of CC chemokines in the lung orchestrates allergic inflammation and airway hyperresponsiveness. J Exp Med 1998;188:157-67.

55. Sallusto F, Lenig D, Mackay CR, Lanzavecchia A. Flexible programs of chemokine receptor expression on human polarized T helper 1 and 2 lymphocytes. J Exp Med 1998;187:875-83.

56. Ohta M, Kitadai Y, Tanaka S, Yoshihara M, Yasui W, Mukaida N, et al. Monocyte chemoattractant protein-1 expression correlates with macrophage infiltration and tumor vascularity in human gastric carcinomas. Int J Oncol 2003;22:773-8.

57. Sato K, Kuratsu J, Takeshima H, Yoshimura T, Ushio Y. Expression of monocyte chemoattractant protein-1 in meningioma. J Neurosurg 1995;82:874-8.

58. Valković T, Dobrila F, Melato M, Sasso F, Rizzardi C, Jonjić N, et al. Correlation between vascular endothelial growth factor, angiogenesis, and tumor-associated macrophages in invasive ductal breast carcinoma. Virchows Arch 2002;440:583-8.

59. Dixon DA, Tolley ND, Bemis-Standoli K, Martinez ML, Weyrich AS, Morrow JD, et al. Expression of COX-2 in platelet-monocyte interactions occurs via combinatorial regulation involving adhesion and cytokine signaling. J Clin Invest 2006;116:2727-38.

60. Weyrich AS, Elstad MR, McEver RP, McIntyre TM, Moore KL, Morrissey JH, et al. Activated platelets signal chemokine synthesis by human monocytes. J Clin Invest 1996;97:1525-34.

61. Juliano RL, Haskill S. Signal transduction from the extracellular matrix. J Cell Biol 1993;120:577-85.

62. FitzGerald GA. COX-2 and beyond: Approaches to prostaglandin inhibition in human disease. Nat Rev Drug Discov 2003;2:879-90.

63. Mickelson JK, Lakkis NM, Villarreal-Levy G, Hughes BJ, Smith CW. Leukocyte activation with platelet adhesion after coronary angioplasty: A mechanism for recurrent disease? J Am Coll Cardiol 1996;28:345-53.

64. Irving PM, Macey MG, Shah U, Webb L, Langmead L, Rampton DS, et al. Formation of platelet-leukocyte aggregates in inflammatory bowel disease. Inflamm Bowel Dis 2004;10:361-72.

65. Miladiyah I, Jumina J, Haryana SM, Mustofa M. In silico molecular docking of xanthone derivatives as cyclooxygenase-2 inhibitor agents. Int J Pharm Pharm Sci 2017;9:98.

66. Chaithanya KK, Gopalakrishnan VK, Hagos Z, Rao DG. Mesuaferrin a-bioactive flavonoid isolated from the bark of Mesua ferrea 1 . against phospholipase a2, cyclooxygenase and lipoxygenase: An in vitro, in vivo and in silico approach. Int J Pharm Pharm Sci 2018;10:102. 